\title{
YB-1 and CTCF Differentially Regulate the 5-HTT Polymorphic Intron 2 Enhancer Which Predisposes to a Variety of Neurological Disorders
}

\author{
Elena Klenova, ${ }^{1}$ Alison C. Scott, ${ }^{2,3}$ Julian Roberts, ${ }^{1}$ Shaharum Shamsuddin, ${ }^{1,5}$ Elizabeth A. Lovejoy, ${ }^{3}$ \\ Stephan Bergmann, ${ }^{6}$ Vivien J. Bubb, ${ }^{3,4}$ Hans-Dieter Royer, ${ }^{7}$ and John P. Quinn ${ }^{2,3}$ \\ ${ }^{1}$ Department of Biological Sciences, University of Essex, Essex C04 3SQ, United Kingdom, ${ }^{2}$ Physiology Laboratory, Departments of ${ }^{3}$ Human Anatomy and \\ Cell Biology and ${ }^{4}$ Neurological Science, Medical School, University of Liverpool, Liverpool L69 3BX, United Kingdom, ${ }^{5}$ School of Health Sciences, University \\ Sains Malaysia, 16150 Kubang Kerian, Kelantan, Malaysia, ${ }^{6}$ Department of Pathology, Memorial Sloan-Kettering Cancer Center, New York, New York \\ 10021, and 7Breast Cancer Research, Center of Advanced European Studies and Research, 53175 Bonn, Germany
}

The serotonin transporter (5-HTT) gene contains a variable number tandem repeat (VNTR) domain within intron 2 that is often associated with a number of neurological conditions, including affective disorders. The implications of this polymorphism are not yet understood, however, we have previously demonstrated that the 5-HTT VNTR is a transcriptional regulatory domain, and the allelic variation supports differential reporter gene expression in vivo and in vitro. The aim of this study was to identify transcription factors responsible for the regulation of this VNTR. Using a yeast one-hybrid screen, we found the transcription factor Y box binding protein 1 (YB-1) interacts with the 5-HTT VNTR. Consistent with this, we demonstrate in a reporter gene assay that the polymorphic VNTR domains differentially respond to exogenous YB-1 and that YB-1 will bind to the VNTR in vitro in a sequence-specific manner. Interestingly, the transcription factor CCTC-binding factor (CTCF), previously shown to interact with YB-1, interferes with the ability of the VNTR to support YB-1-directed reporter gene expression. In addition, CTCF blocks the binding of YB-1 to its DNA recognition sequences in vitro, thus providing a possible mechanism of regulation of YB-1 activation of the VNTR by CTCF. Therefore, we have identified YB- 1 and CTCF as transcription factors responsible, at least in part, for modulation of VNTR function as a transcriptional regulatory domain. Our data suggest a novel mechanism that explains, in part, the ability of the distinct VNTR copy numbers to support differential reporter gene expression based on YB-1 binding sites.

Key words: CTCF; YB-1; 5-HTT; VNTR; affective disorders; transcription

\section{Introduction}

Mutation or inappropriate expression of the serotonin transporter (5-HTT) gene has been postulated as a possible predisposing factor in many CNS-related disorders, including numerous studies of affective disorders. The human gene encompasses 15 exons spanning $\sim 31 \mathrm{~kb}$ on chromosome $17 \mathrm{q} 11$ (Lesch et al., 1994). No differences in amino acid sequence have been found between healthy controls and affective disorder patients, however, associations between two polymorphisms found in noncoding regions of the 5-HTT gene and susceptibility to affective disorder have been reported (Collier et al., 1996; Battersby et al.,

\footnotetext{
Received March 29, 2004; revised May 11, 2004; accepted May 13, 2004.

This work was supported by grants from the Wellcome Trust, Biotechnology and Biological Sciences Research Council, Medical Research Council (all to J.P.Q.), and the Breast Cancer Campaign (E.K.); a PhD scholarship from the Malaysian Government (S.S.); and a PhD studentship from the University of Essex (J.R.). We are grateful to A. Lee and J. Ting for the YB-1 vector constructs and antibodies and I. Chernukhin for providing us with the purified bvCTCF samples.

Correspondence should be addressed to either of the following: Dr. John Quinn, Department of Human Anatomy and Cell Biology, Medical School, University of Liverpool, Liverpool L693BX, UK, E-mail:jquinn@liv.ac.uk; or Dr. Elena Klenova, Department of Biological Sciences, University of Essex, Wivenhoe Park, Colchester, Essex C04 3SQ, UK, E-mail:klenovae@essex.ac.uk.

DOI:10.1523/JNEUROSCI.1150-04.2004

Copyright $\odot 2004$ Society for Neuroscience $\quad 0270-6474 / 04 / 245966-08 \$ 15.00 / 0$
}

1997; Heils et al., 1997; Mellerup et al., 2001; Bellivier et al., 2002). This association, nevertheless, remains controversial because it has not always been reproducible (Hoehe et al., 1998). We have been addressing the function of one of these polymorphisms within intron 2 of the 5-HTT gene, which is also potentially a predisposing factor for a number of other neurological disorders such as attention deficit hyperactivity disorder and autism (Kent et al., 2002; Conroy et al., 2004). Three allelic variants of this variable number tandem repeat (VNTR) (Stin2.9, Stin2.10, and Stin2.12) containing, respectively, 9, 10, or 12 copies of a repeated 16 or 17 bp element have been identified (Battersby et al., 1996; Ogilvie et al., 1996; Ogilvie and Harmar, 1997) (see Fig. 1). We have demonstrated that the different repeat number within the VNTR supports differential expression in vitro (Fiskerstrand et al., 1999; Lovejoy et al., 2003) and both differential and tissuespecific expression in vivo (MacKenzie and Quinn, 1999) in a transgenic model. It has also been demonstrated that the VNTR genotype correlates with the number of platelet 5-HTT transporters in patients with affective disorders (Mellerup et al., 2001). Characterization of the transcription factors that bind to the VNTR and determination of their ability to support differential expression is one approach to identify the signal transduction 
pathways contributing to neurological disorders in which these 5-HTT intron 2 polymorphisms are implicated.

Here, we report the first identification of transcription factors that mediate differential expression supported by the VNTRs. We demonstrate that the 5-HTT intron 2 VNTR is bound and regulated by the $\mathrm{Y}$ box binding protein 1 (YB-1) transcription factor, a member of the large family of Y box binding proteins (Wolffe et al., 1992; Wolffe, 1994; Swamynathan et al., 1998; Kohno et al., 2003). YB-1 regulation of the VNTR is modulated by the transcription factor CCTC-binding factor (CTCF), which we have identified previously as a binding partner of YB-1 (Chernukhin et al., 2000). CTCF, in addition to transcriptional silencing or activating in a context-dependent manner, organizes epigenetically controlled chromatin insulators that regulate imprinted genes in soma (Klenova et al., 1993; Filippova et al., 1996; Ohlsson et al., 2001; Klenova et al., 2002). CTCF has been implicated previously in the deregulation of other neuronal-specific genes (Vostrov and Quitschke, 1997; Burton et al., 2002; Vostrov et al., 2002). Our data and model for regulation of the VNTR provides insights into the molecular mechanisms associated with development of neurological disorders in which the 5-HTT gene is implicated.

\section{Materials and Methods}

Yeast one-hybrid screen. The yeast one-hybrid assay was conducted using the MATCHMAKER One-Hybrid System, and all experimental procedures were performed according to the manufacturer's instructions (Clontech, Cambridge, UK). Briefly, the Stin2.10 VNTR DNA (MacKenzie and Quinn, 1999) was used as bait to identify interacting proteins expressed from a human fetal brain MATCHMAKER cDNA library (Clontech). Diploid yeast clones were obtained that contained individual plasmids from the cDNA library. Plasmid DNA was isolated according to the manufacturer's instructions, using a yeast DNA isolation system (Stratagene, La Jolla, CA). The plasmids were then subjected to DNA sequence analysis to determine which cDNAs they encoded. Verification of binding was as per the manufacturer's instructions.

Plasmids. The full-length cDNA for the $Y B-1$ gene was subcloned from the pSFFV-YB-1 plasmid, obtained as a kind gift from Dr. J. Ting (University of North Carolina, Chapel Hill, NC), into the mammalian expression vector pcDNA3 (Invitrogen, San Diego, CA). The expression plasmid for the chicken CTCF gene, pCTCF, has been described previously (Klenova et al., 2001). The reporter constructs Stin2.9, Stin2.10, and Stin2.12 use the luciferase reporter construct pGL3P and were reported previously (Fiskerstrand et al., 1999).

Cell cultures, transient transfections, and luciferase assay. COS7 and HEK (human embryonic kidney) 293T cells were maintained in DMEM supplemented with $10 \% \mathrm{FCS}$ and $50 \mu \mathrm{g} / \mathrm{ml}$ gentamycin. Cells were transfected using a standard calcium precipitation method (Sambrook and Russell, 2001). A total of $10^{5}$ cells was plated in a 12 -well plate format and transfected (0.5-3 $\mu \mathrm{g}$ plasmid per well) after a $24 \mathrm{hr}$ growth with the reporter gene and expression vectors. To normalize for cell number and transfection efficiency, $0.25 \mu \mathrm{g}$ of $\beta$-galactosidase marker gene vector (pCH110) was added per well. Cells were washed $24 \mathrm{hr}$ after transfection, harvested at $48 \mathrm{hr}$, and assayed using the Luciferase Assay System (Promega, Madison, WI) and Labsystems Luminoskan (Life Sciences, Hialeah, FL), according to the manufacturers' instructions.

Transfections were performed in triplicate in at least three independent experiments, and the mean normalized luciferase values were calculated together with the SEM.

Expression and purification of the recombinant $Y B-1$ and CTCF proteins. Five YB-1 variants were constructed, in a modified pGEX-2T expression vector using the $\mathrm{NcoI}$ and EcoRI sites. Briefly, primers containing the $\mathrm{NcoI}$ and EcoRI restriction sites (sequences available on request) were used for PCR amplification. The fragments were designed as described previously (Jurchott et al., 2003): pGEX-YB-1(1) contains aa 21-317, pGEX-YB-1(2) contains aa 21-225, pGEX-YB-1(3) contains aa 21-147, pGEX-YB-1(4) contains aa 146-317, and pGEX-YB-1(5) contains aa 146-225. A schematic representation of each mutant is shown in Figure
4A. The PCR fragments were subcloned into the intermediate vector pGEM-T (Promega), excised, ligated into the NcoI/EcoRI sites of the vector pGEX-2T (Amersham Pharmacia Biotech), and the recombinant constructs were verified by sequencing.

Transformation of Escherichia coli and induction of the glutathione $S$-transferase (GST) fusion proteins were performed as reported by Smith and Johnson (1988) and Klenova et al. (1997). The expressed truncated YB-1 proteins were prepared by sonication in binding buffer (50 mm Tris-Cl, pH 8.0, 1 mм EDTA, 120 mм NaCl, 0.5\% NP-40, 10\% glycerol, and $1 \mathrm{~mm}$ PMSF). Purification of the CTCF protein expressed in the baculovirus system was performed according to Chernukhin et al. (2000).

EMSA and Western blot analysis. The conditions for EMSA and Western blot analysis were as reported previously (Chernukhin et al., 2000). The double-stranded DNA fragments for EMSA were obtained by PCR as according to Fiskerstand et al. (1999). Primers for amplification were as follows: VNTR forward, 5'-ATGGCGCGCCGGTACCTCACAGGCTGCGAGTAGA-3'; VNTR reverse, 5' -AACGGCGCGCCTCGAGTGGCCTCTCTCAAGAGGA-3'; T7 primer, 5'-TAATACGACTCACTATAGGG-3'; U19 primer, 5'-GTTTTCCCAGTCACGACGT-3'.

We also used the annealed primers corresponding to the YB-1 binding sites designed as follows: (1) VNTR 3/4 (HindIII/XbaI ends, SmaI is in italics): AGCTTGACCCGGGGTGGGCTGTGAT, ACTGGGCCCCACCCGACACTAGATC; (2) VNTR 6/7 (HindIII/XbaI ends, SmaI is underlined): AGCTTCCTGGGATGGGCTGTGACCCGGGT, AGGACCCTACCCGACACTGGGCCCAGATC; (3) YB-1 from mdr-1 (Jurchott et al., 2003) (HindIII/XbaI ends, ApaI is underlined): AGCTTGAGGCTGATTGGCTGGGCCCT, ACTCCGACTAACCGACCCGGGAGATC; (4) YB-1 from mdr-1 mut (HindIII/XbaI ends, ApaI is underlined, mutated nucleotides are shown in bold italic): AGCTTGAGGCTCAGTACTTGGGCCCT, ACTCCGAGTCATGAACCCGGGAGATC.

Production of in vitro translated deletion mutants of $Z n$ finger domains. To generate the $\left[{ }^{35} \mathrm{~S}\right]$ Met-labeled full-length CTCF-Zn finger (ZF) domain, we used plasmid p4a-ZF (1-11) (Filippova et al., 1996). In vitro translation was performed according to the protocol suggested by the manufacturer (Promega).

In vitro interaction assay using the immobilized CTCF-ZF domain. Sonicated bacterial lysates containing YB-1 derivatives were used in the interaction experiments. Bacterial lysate was passed through the matrix with the immobilized CTCF-ZF domain, prepared as described previously (Chernukhin et al., 2000). After washing three times in the high-salt binding buffer (50 mм Tris-Cl, pH 8.0, 1 mм EDTA, $500 \mathrm{~mm} \mathrm{NaCl}, 0.5 \%$ NP-40, 10\% glycerol, and $1 \mathrm{~mm}$ PMSF), the samples were subjected to SDS-PAGE and immunoblotted with anti-GST goat antibody (Amersham Biosciences, Piscataway, NJ).

In vitro interaction assay using the immobilized YB-1 mutants. The bacterial lysates of truncated YB-1 deletion mutants were produced and coupled with glutathione-Sepharose, as described previously (Smith and Johnson, 1988). The interaction assay was performed as follows: $2 \mu$ l of in vitro translated ZF11 was mixed with $50 \mu \mathrm{l}$ of each individual YB-1 mutant bound to glutathione-Sepharose beads in $500 \mu \mathrm{l}$ of binding buffer ( $50 \mathrm{~mm}$ Tris-Cl, pH 7.4, $150 \mathrm{~mm} \mathrm{NaCl}, 5 \mathrm{~mm}$ EDTA, 0.5\% NP-40, and $1 \mathrm{~mm}$ PMSF) for $4 \mathrm{hr}$ at $4^{\circ} \mathrm{C}$. The complexes were washed three times in washing buffer ( $50 \mathrm{~mm}$ Tris- $\mathrm{Cl}, \mathrm{pH}$ 7.4, $500 \mathrm{~mm} \mathrm{NaCl}, 5 \mathrm{~mm}$ EDTA, $0.5 \% \mathrm{NP}-40$, and $1 \mathrm{~mm}$ PMSF), and the proteins bound to beads were eluted with protein sample buffer and separated by SDS-PAGE. The gel was then fixed and vacuum dried for $2 \mathrm{hr}$ at $75^{\circ} \mathrm{C}$ and exposed to $\mathrm{x}$-ray film overnight at $-70^{\circ} \mathrm{C}$.

\section{Results}

\section{Yeast one-hybrid screening}

Initial screening of the pretransformed human fetal brain cDNA library generated candidate diploid clones of potential interest. Clones were picked at random, and levels of marker gene expression within these clones were analyzed further, and several clones were identified as candidates for plasmid isolation. The nature of cDNA inserts present was then determined by DNA sequence analysis. Several clones contained a fragment of cDNA for the 
A

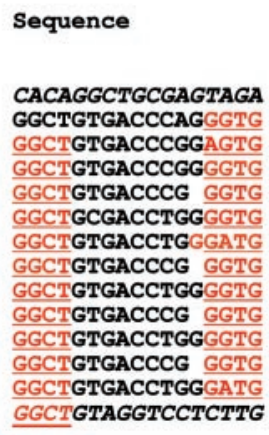

Potential YB-1 binding sites within Stin2.12 VNTR used in EMSA

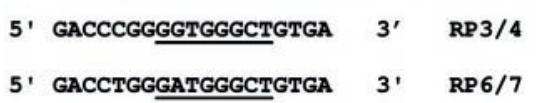

B

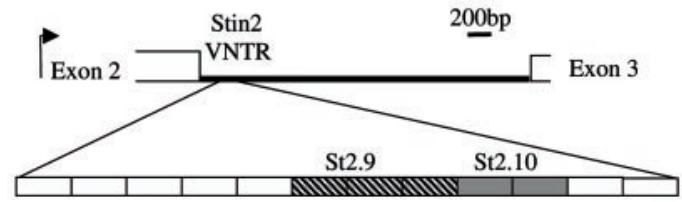

$\begin{array}{llllllllllll}\text { RP1 } & \text { RP2 } & \text { RP3 } & \text { RP4 } & \text { RP5 } & \text { RP6 } & \text { RP7 } & \text { RP8 } & \text { RP9 } & \text { Rp10 } & \text { Rp11 } & \text { RP12 }\end{array}$

Figure 1. Schematic representation of the structure and sequence of the Stin 2 VNTR. A, The Stin 2.12 VNTR sequence showing individual repeats (RP1 through RP12) and unique elements based on primary sequence $(a, b, c, d, e, f, g)$. Potential YB-1 binding sites are underlined, and two sequences were selected from the repeats $3 / 4$ and $6 / 7$ and analyzed further in EMSA. $B$, VNTR polymorphisms within the serotonin transporter intron 2. Two distinct polymorphisms, St2.10 and St2.9, vary in the location and number of deletions of the repeats as indicated by St2.10 (filled boxes) or St2.9 (hatched boxes). Transcription start site is indicated by an arrow.

human YB-1 (GenBank accession number J03827) (Didier et al., 1988). The cDNA was complete, except for a short N-terminal truncation corresponding to the first 18 amino acids of the fulllength wild-type protein.

Inspection of the VNTR sequence identified several potential binding sites for YB-1 spanning the region between the individual repeat elements (Fig. $1 A$, red) that would be in agreement with the consensus of the recognition motif for the family of $\mathrm{Y}$ box binding proteins (Fig. 1A) (Didier et al., 1988; Wolffe et al., 1992; Wolffe, 1994). The identification of this protein was significant because its DNA-binding consensus sequences, depending on the alignments of a G-rich stretch within or flanking the potential YB-1 site, are located in the area that predominantly both demonstrates primary sequence variation between the individual repeats in the VNTR and the variation that accounts for the difference in size of the repeats, either 16 or 17 nucleotides (Fig. $1 A$ ). This suggested strongly to us that YB-1 not only might affect expression supported by the VNTR but also the differential expression observed. Thus, in our initial studies reported here, it was decided to determine whether $\mathrm{YB}-1$ played any role in transcription supported by the VNTR in intron 2 .

YB-1 can specifically and differentially activate the distinct VNTR domains in a tissue-specific manner in a cotransfection assay

We have previously demonstrated the ability of the VNTR domains to support reporter gene expression in vivo and in vitro
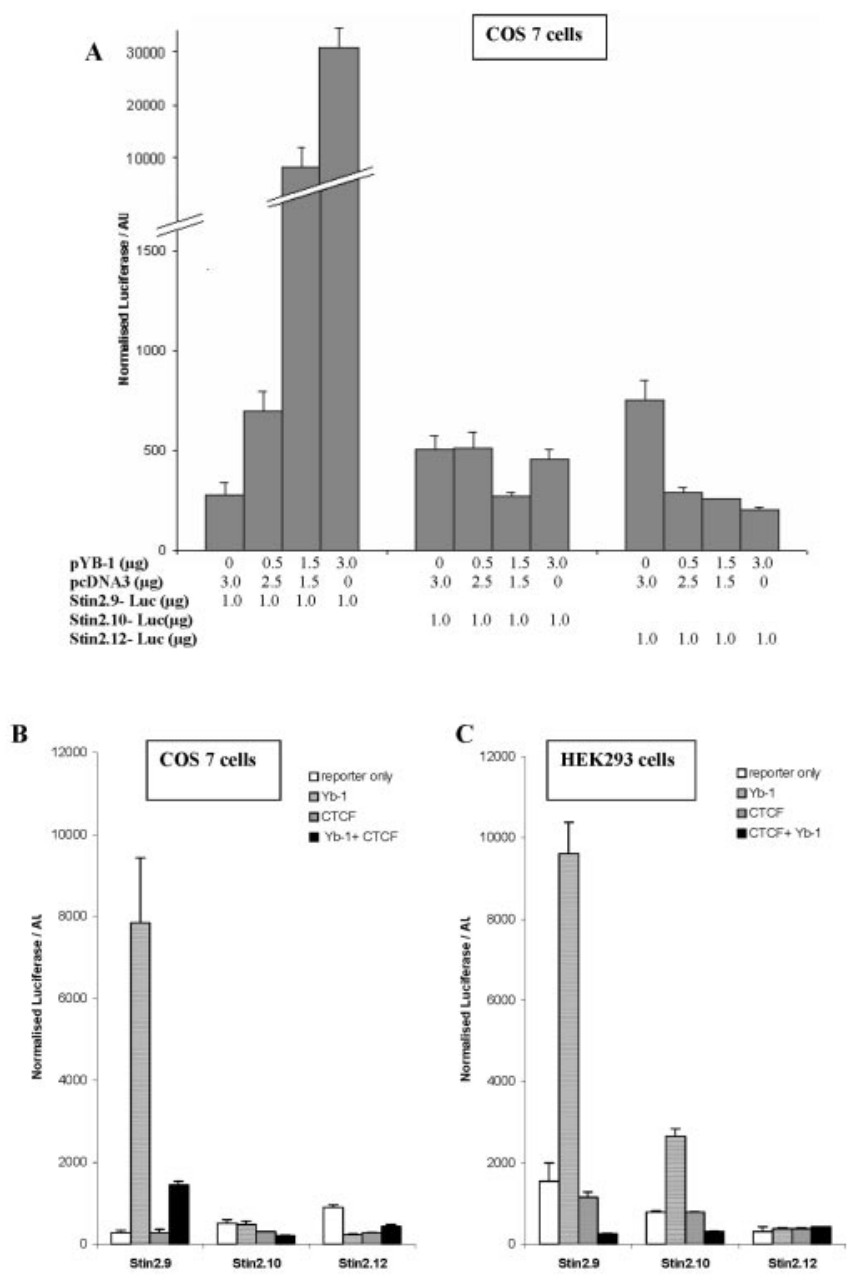

Figure 2. YB-1 differentially activates the distinct VNTR domains in a cell-specific manner, and CTCF abrogates the activating function of YB-1. Cells were transfected, and luciferase assays were performed. Transfections were performed in triplicate in at least three independent experiments, and the mean normalized luciferase values were calculated together with the SEM, represented by error bars. $A$, Titration of pYB-1 plasmid with $1 \mu \mathrm{g}$ of luciferase reporter in COS7 cells. B, Cotransfection of CTCF, YB-1, and the VNTR-luciferase reporters into COS7 cells. C, Cotransfection of CTCF, YB-1, and the VNTR-luciferase reporters into HEK 293T cells.

(Fiskerstrand et al., 1999; MacKenzie and Quinn, 1999; Lovejoy et al., 2003). To further investigate the ability of YB-1 to regulate the VNTR domains, we used luciferase reporter gene constructs containing VNTR domains inserted upstream of the SV40 promoter termed pStin2.9Luc, pStin2.10Luc, and pStin2.12 Luc. A series of standard cotransfection assays were performed with these reporter constructs and with a vector expressing full-length YB-1 (pYB-1) in COS7 cells. We found that YB-1 can differentially regulate the polymorphic VNTR domains in these cells. As shown in Figure $2 \mathrm{~A}$, the most significant effect was observed from the Stin2.9 VNTR variant, which was strongly and progressively activated by increasing amounts of pYB-1. In COS7 cells, the reporter gene pStin2.10 Luc did not respond to exogenous YB-1, and the plasmid pStin2.12 Luc was slightly repressed with increasing amounts of pYB-1. YB-1 can also exert a cell-specific affect, because we demonstrated that Stin 2.10 is activated in addition to Stin2.9 in HEK 293T cells (Fig. 2C). The latter suggests evidence for cell-specific factors that can directly modulate the function of YB-1 or that differentially affect VNTR function. 
A

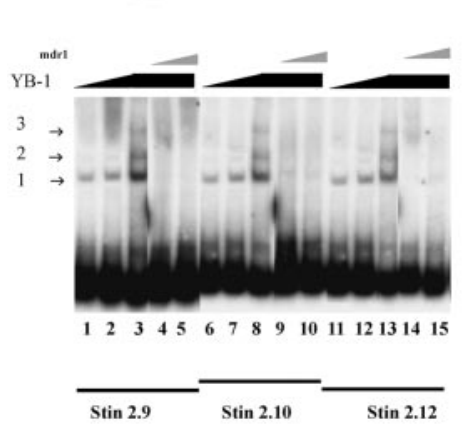

C

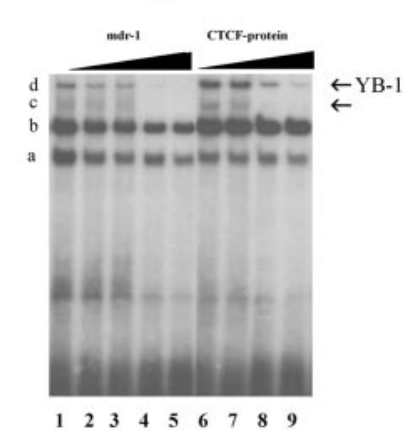

B

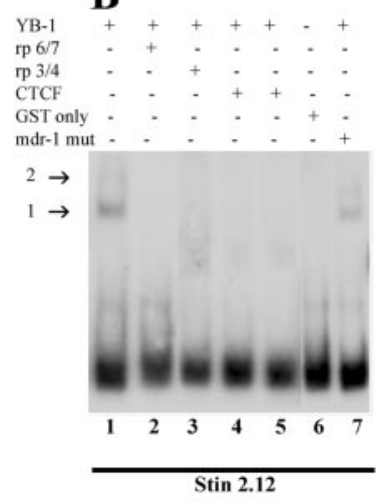

D

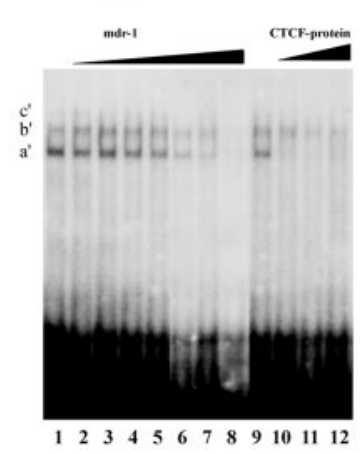

Figure 3. Analysis of the YB-1 interactions with VNTR domains in EMSA. A, Bacterially expressed YB-1 can form specific complexes with the ${ }^{32}$ P-labeled Stin 2.9, Stin 2.10, and Stin 2.12 DNA. Each incubation mixture contained the same amount of nonspecific competitor poly(deoxyinosinic-deoxycytidylic) acid (dldC) $(0.1 \mu \mathrm{g}) ; 1 \mu \mathrm{g}$ of GST-YB-1 fusion was added to samples in lanes 1, 6, and 11; $2 \mu \mathrm{g}$ of GST-YB-1 was added to samples in lanes 2, 7, and 12; 4 $\mu \mathrm{g}$ of GST-YB-1 was added to samples in lanes $3-5,8-10$, and $13-15$. The specific competitor mdr- 1 oligonucleotide was added as follows: lanes 4 and 9, and 14- to 50-fold molar excess; lanes 5 and 10, and 15- to 100-fold molar excess. The positions of DNA-protein complexes are indicated (labeled 1, 2, and 3). B, Competition EMSA analysis. The labeled Stin 2.12 DNA fragment was incubated with the same amount of nonspecific competitor dldC $(0.1 \mu \mathrm{g})$ and $2 \mu \mathrm{g}$ of GST-YB-1 protein in all reactions (except 6 , in which a $2 \mu \mathrm{g}$ of GST component of the fusion protein was added). Competitors tested in this experiment were as follows: lane 2, 100-fold molar excess of rp 6/7 oligonucleotide; lane 3, 100-fold molar excess of $\mathrm{rp} 3 / 4$ oligonucleotide; lane $4,0.5 \mu \mathrm{g}$ of baculoCTCF; lane 5, $1 \mu \mathrm{g}$ of baculoCTCF; lane $6,2 \mu \mathrm{g}$ of GST; lane 7, 100-fold excess of the mdr-1 mutated oligonucleotide that is unable to bind YB-1.C, EMSA analysis of the competition with rp 3/4-GST-YB-1 complexes. Incubation mixtures contained labeled rp 3/4 oligonucleotide, nonspecific competitor dIdC $(0.1 \mu \mathrm{g})$, and $2 \mu \mathrm{g}$ of GST-YB-1. DNA-protein complexes were preformed during a 30 min incubation on ice, then the competitors were added, and incubation continued for an additional $20 \mathrm{~min}$. Competitors were added as follows: lane 1, no competitor; lanes 2-5, 10-, 25-, 50-, and 100-fold molar excess of oligonucleotide mdr-1, respectively; lanes $6-9,0.25,0.5,1$, and $2 \mu \mathrm{g}$ of baculoCTCF, respectively. D, EMSA analysis of the competition with rp 6/7-GST-YB-1 complexes. The incubation mixtures contained labeled rp $6 / 7$ oligonucleotide, nonspecific competitor dldC $(0.1 \mu \mathrm{g})$, and $2 \mu \mathrm{g}$ of GSTYB-1. In C and D, DNA-protein complexes were preformed during a 30 min incubation on ice, then the competitors were added, and incubation continued for an additional $20 \mathrm{~min}$. Competitors were added as follows: lane 1, no competitor; lanes 2-8, 10-, 25-, 50-, 100-, 150-, 200-, and 250 -fold molar excess of oligonucleotide mdr-1, respectively; lanes $9-12,0.25,0.5,1$, and $2 \mu \mathrm{g}$ of baculoCTCF, respectively.

\section{YB-1 binds to Stin2 VNTR in vitro}

To confirm that the VNTR domain contain binding sites for YB-1 protein, we performed EMSA analysis using end-labeled products of Stin2.9, Stin2.10, and Stin2.12. As shown in Figure 3A, all three fragments form complexes with the bacterially produced, purified GST-YB-1 fusion protein. The specificities of these complexes were confirmed because bands were not detected with the
GST component of the fusion protein (Fig. 3B, lane 6). Complex 1 was detected only when $0.5 \mu \mathrm{g}$ of YB- 1 was used in the EMSA reaction; however, complexes 2 and 3 could be seen with increasing amounts of YB-1 protein (Fig. $3 A$, lanes $1-3,6-8$, and 1113). Complexes 1,2, and 3 may reflect the occupancy of different sites within the VNTR domain by YB-1 as increasing amounts of this protein are added to the reaction or result from multimerization of YB-1 (Izumi et al., 2001). All three bands were competed when unlabeled mdr- 1 sequences containing the well characterized YB-1 binding site were included in the reaction (Fig. $3 \mathrm{~A}$, lanes 4 and 5, 9 and 10, and 14 and 15). This competition was not observed using the mutated mdr-1 oligonucleotide (Fig. 3B, lane 7 ), thus confirming multiple sequence-specific YB-1 binding sites are present in all three VNTR domains.

\section{Characterization of two classes of potential YB-1 binding sites, dependent on primary DNA sequence, within the VNTR domains}

The majority of the YB-1 sites identified within the longest VNTR domain, Stin2.12, have the core sequence GGTGGGCT, but one site has the YB-1 binding site core sequence, GATGGGCT (Fig. $1 A)$. For additional analysis, we designed oligonucleotides containing these two variants of the YB-1 binding sequence (YB-1 site 1 , termed rp 3/4, and YB-1 site 2, termed rp 6/7). When these were used in EMSA experiments competing with the longest VNTR domain, Stin2.12, both oligonucleotides were able to dissociate YB-1-VNTR complexes (Fig. 3B), providing evidence that these sites are involved in the formation of these complexes.

Additional experiments shown in Figure $3 C$ demonstrate that YB-1 produces four complexes with rp 3/4, however, only two complexes, $\mathrm{d}$ and $\mathrm{c}$, are efficiently removed by competition with the double-stranded mdr-1 oligonucleotide (lanes 1-5). The oligonucleotide rp 6/7, corresponding to the second type of potential YB-1 site, generated a different binding pattern with YB-1 protein (Fig. 3D, lane 1). Two complexes are clearly seen with a very faint slower migrating complex $\left(c^{\prime}\right)$ occasionally observed. All binding to this site can be removed by competition from the mdr-1 oligonucleotide. However, a greater concentration of the oligonucleotide is required to dissociate complexes $\mathrm{a}^{\prime}$ and $\mathrm{b}^{\prime}$ than the specific complexes observed on rp 3/4 (Fig. 3D, lanes 2-8).

\section{Binding of YB-1 to the VNTR is inhibited by CTCF}

We have previously demonstrated that YB-1 interacts with the transcription factor CTCF (Chernukhin et al., 2000). Therefore, we investigated whether CTCF would modulate YB-1 binding to the Stin12 VNTR-YB-1, rp 3/4-YB-1, and rp 6/7-YB-1 complexes. As shown in Figures $3 B$ (lanes 4 and 5), 3C (lanes 6-9), and $3 D$ (lanes 9-12), CTCF produced in the baculoviral system could dissociate complexes of YB-1 from the full-length VNTR domain (Stin2.12) and the individual VNTR elements. This inhibition of YB-1 binding could be via the CTCF protein binding more avidly to the DNA, and stereotaxically inhibiting YB-1 interactions or CTCF could bind toYB-1 in a manner that blocked the YB-1 DNA binding domain recognizing the consensus sequence. We postulated the latter because (1) we have previously observed YB-1-CTCF interactions via the CTCF ZF domain (Chernukhin et al., 2000) and (2) binding of CTCF rather than YB-1 to the VNTR sequence would have led to the appearance of complexes that would be observed in our EMSA; clearly these are not seen under our experimental conditions in Figure 3. 


\section{CTCF abrogates YB-1-induced reporter gene supported by VNTRs Stin2.9 and Stin2.10}

To investigate whether CTCF interferes with the activating function of YB-1 on the VNTR, we performed transient cotransfection assays using vectors expressing the full-length CTCF (pCTCF) and YB-1 (pYB-1) and the reporter gene plasmids containing the VNTR domains. As shown in Figure 2, $B$ and $C$, CTCF alone has no effect on the expression from all three reporter plasmids. However, when pCTCF was cotransfected together with pYB-1 and the reporter gene plasmid containing Stin2.9, CTCF strongly inhibited expression of the reporter in both cell lines tested (COS7 and HEK 293T). CTCF also interfered with the activation of the Stin2.10 reporter construct by YB-1 in HEK $293 \mathrm{~T}$ (Stin2.10 was not activated by YB-1 in COS7 cells).

\section{Determination of possible mechanisms by which CTCF can antagonize YB-1 regulation of the VNTR}

To gain insight into a possible mechanism of CTCF function in the regulation of YB-1 and VNTR domains, we aimed to determine the specific region of the $\mathrm{YB}-1$ protein involved in the interaction with the ZF domain of CTCF. For this purpose, we produced a series of truncated variants of the YB-1 protein in $E$. coli. These proteins are schematically shown in Figure $4 \mathrm{~A}$. Immunoblotting with an anti-GST antibody was used to reveal the expressed proteins (Fig. $4 \mathrm{~B}$ ). Of all fusion proteins tested, only GST-YB-1(5) migrated according to its predicted size. The anomalous migration of these GST-fused YB-1 constructs was probably attributable to particular amino acid composition and has been observed by other researchers working with GST-fused YB-1 (MacDonald et al., 1995). Interestingly, the GST-YB-1(4) migrated as a triplet. This YB-1 truncated variant consists of the C-terminal domain of YB-1 and contains a series of four alternating basic and acidic regions that could also be very sensitive to spontaneous degradation (Sommerville and Ladomery, 1996). Therefore, it is likely that the two slower migrating bands may be the products of such degradation. Anomalous electrophoretic migration of this mutant could be attributed to negative charges (anomalous migration of negatively charged protein is quite common) and has been observed in the E. coli ams protein (Casaregola et al., 1992) and the C-terminal domain of CTCF (Klenova et al., 1997).

The bacterially expressed CTCF-ZF domain was prepared and verified with both Coomassie staining and Western assay and coupled with the thiol-activated Sepharose as described previously (Chernukhin et al., 2000). The interaction assay was then performed using the truncated YB-1 proteins. As shown in Fig. $4 C$, YB-1(1), YB-1(2), and YB-1(3) revealed clear interaction with the immobilized $\mathrm{ZF}$ domain because the proteins corresponding to the cognate bacterially produced GST-YB-1(1), GST-YB-1(2), and GST-YB-1(3) were retained by CTCF-ZF. The minimal protein sequences required for interaction in this assay were the $\mathrm{N}$-terminal sequences containing the DNAbinding cold shock domain (CSD). When these sequences were removed [GST- YB-1(4) and GST-YB-1(5)], no signal was detected from the interaction assay. It should be noted in Figure $4 C$, weak signal from a protein(s) with a molecular weight of $\sim 60$ $\mathrm{kDa}$ has been detected interacting with YB-1(2) and YB-1(3) and possibly YB-1(1) and YB-1(4). We were unable to determine the nature of this protein, and it is unresolved whether these interactions are nonspecific or attributable to homomeric formation of YB-1 (Gaudreault et al., 2004), as might be suggested from YB-1(4) interactions.

The ability of GST-YB-1(1), GST-YB-1(2), and GST-YB-1(3)

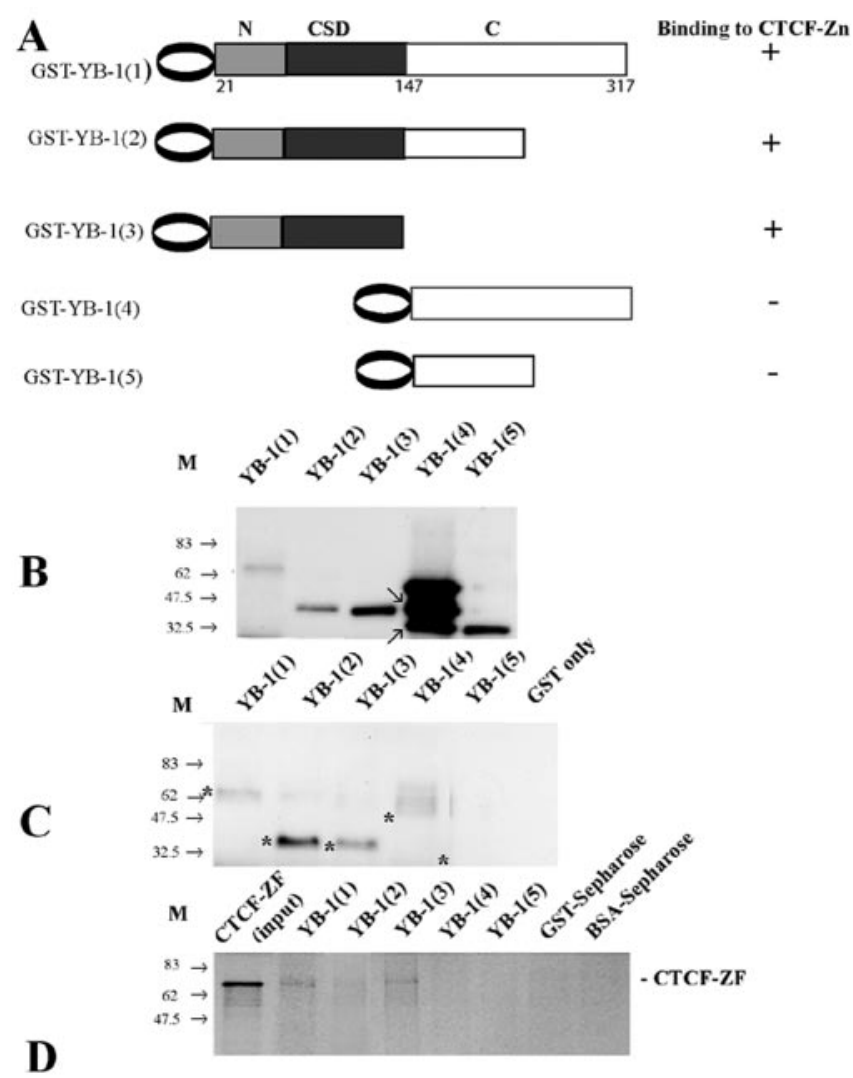

Figure 4. YB-1 interacts with CTCF in the region that contains the YB-1 CSD. A, Schematic representation of the truncated versions of GST-YB-1. Gray box, N-terminal domain; black box, CSD; open box, C-terminal domain. The ovals represent the GST portion of each truncated variant. $B$, Western blot of the truncated YB-1 variants expressed in $E$. coli. The fusion proteins were prepared as described in Materials and Methods, resolved in 10\% SDS-PAGE and probed with the anti-GST-1 antibody. The arrows indicate the positions of degraded GST-YB-1(4) protein. $C$, In vitro interaction assay between the CTCF-ZF domain coupled with the matrix and a panel of truncated YB-1 variants expressed in E. coli. For the interaction assay, the CTCF-Zn domain coupled with Sepharose was incubated individually with the GST-YB-1 variants, then washed with $0.25 \mathrm{~m}$ radioimmunoprecipitation assay (RIPA) buffer. Proteins retained on the matrices were analyzed by SDS-PAGE, followed by immunoblotting with the anti-GST-1 antibodies. The GST protein was used as a control. Asterisks at the left side of the lanes show the positions of cognate proteins seen in B.D, In vitro interaction assay between theYB- 1 truncated variants expressed in $E$. coli and immobilized on the matrix and CTCF-ZF domain. The ${ }^{35} \mathrm{~S}-$ labeled CTCF-Zn domain was generated by an in vitro translation and was incubated with matrices containing immobilized variants of YB-1, GST bound to Sepharose and Sepharose only, then washed with $0.25 \mathrm{~m}$ RIPA buffer. Proteins retained on the matrices were analyzed by SDS-PAGE, gel dried, and exposed. M, Protein molecular weight markers in kilodaltons.

to interact with the CTCF-ZF was tested in the reverse experiment, in which the truncated variants of YB-1 were immobilized on the matrix and the in vitro translated ${ }^{35} \mathrm{~S}$-labeled ZF domain of CTCF was in solution. As shown in Figure $4 D$, the CTCF-ZF was retained by GST-YB-1(1) and GST-YB-1(3), a weaker signal can be seen in GST-YB-1(2), but no CTCF-ZF was detected with immobilized GST-YB-1(4) and GST-YB-1(5). There was no signal from the labeled ZF domain in either of the negative controls (GST only and BSA-Sepharose), confirming that the YB-1 interaction with CTCF-ZF uses sequences in the N-terminal CSD domains.

\section{Discussion}

The aim of this study was to identify transcription factors responsible for the regulation of the 5-HTT intron 2 VNTR function. We have demonstrated that two proteins, YB-1 and CTCF, play 
an important role in this regulation. Both YB-1 and CTCF are multifunctional and widely expressed transcription factors. These factors are able to modulate the differential expression of the distinct VNTR variants in a reporter gene construct, suggesting that they may play a similar role in vivo.

In this study, the YB-1 protein was identified as a factor interacting with the Stin2 VNTR domains in the yeast "one-hybrid" screen. The longest Stin2.12 domain contains multiple putative YB-1 binding sites (Fig. $1 \mathrm{~A}$, red) that are in agreement with the consensus for the recognition motif for the family of the Y box binding proteins (Didier et al., 1988; Wolffe et al., 1992; Wolffe, 1994). The potential importance of this transcription factor was suggested because its DNA-binding consensus is in the same region of each repeat that predominantly accounts for the variation in primary sequence between the repeats in the VNTR and additionally for the variation that accounts for the difference in size of the repeats of either 16 or $17 \mathrm{bp}$ (Fig. 1).

All three VNTR variants (Stin2.9, Stin2.10, and Stin2.12) and the individual sequences representing two types of YB-1 binding sites within the VNTR (rp 3/4 and rp 6/7) could form specific complexes with YB-1 in EMSA (Fig. 3). rp 3/4 contains the motif GGTG/CACC, and rp 6/7 contains the motif GATG/CATC, which are efficiently recognized by Y-box proteins (Zasedateleva et al., 2002). Although the lengths of the rp $3 / 4$ and rp 6/7 oligonucleotides are similar, the complexes produced by these oligonucleotides in EMSA with the YB-1 protein differ (Fig. 3). Different patterns of YB-1-DNA complexes are, nevertheless, not unusual and were observed previously for cyclin $A$ and cyclin B1 gene $\mathrm{Y}$ boxes (Jurchott et al., 2003). This phenomenon may be explained by the differences in the primary nucleotide sequence of the YB-1 recognition sequence, which may determine the binding characteristics of YB-1 (Spitkovsky et al., 1992). It is now generally accepted that YB-1 functions are, in part, dependent on the DNA secondary structure (Swamynathan et al., 1998; Zasedateleva et al., 2002). It is therefore plausible that a particular composition of the individual repeats in Stin2 VNTR may result in different structural conformation of this regulatory region, thus leading to combinatorial functional outcome. Perhaps, significantly, the rp 6/7 element is deleted in the nine-copy VNTR; this removes the GATGGGCT YB-1 motif, which is underrepresented in the VNTR domain. It is interesting that the nine-copy variant is the most responsive to the exogenous $\mathrm{YB}-1$ addition in the reporter gene analysis discussed below.

In the reporter gene assay, we have observed that differential regulation of the VNTR function by YB-1 was dependent on both the repeat number of the VNTR and the cell type. Specifically, the exogenously supplied YB-1 was able to progressively activate the Stin2.9 domain, in accordance with the increasing input of YB-1, whereas the domains containing the 10- and 12-copy VNTR domain did not respond toYB-1 in COS7 cells. The Stin2.9 domain is a polymorphic variant of the Stin2 VNTR containing a deletion of three repeats ( $\operatorname{rp~} 6, \operatorname{rp~7,~and~} \operatorname{rp~8)}$ ), and the Stin2.10 domain is a polymorphic variant of the Stin2 VNTR with a deletion of two repeats (rp 9 and $\mathrm{rp} 10$ ) (Fig. $1 \mathrm{~B}$ ). Interestingly, the YB-1 binding site 2 (GATGGGCT), which is the underrepresented YB-1 consensus motif, is located inside the sequences deleted in the Stin2.9 domain. We therefore hypothesize that YB-1 bound to site 2 situated within rp 6-rp 7 may have a critical role for determining the function of the VNTR; for example, in cells such as COS7, this site once bound by YB-1 would prevent additional activation of the 5-HTT VNTR by YB-1 in the Stin2.10 and Stin2.12 domains. This might be consistent with binding of YB-1 to this site affecting DNA structure in a manner distinct from the other YB-1 sites
(Zasedateleva et al., 2002); similarly, different YB-1 binding sites, once bound, can differentially alter DNA strand separation (Gaudreault et al., 2004). Thus, modification of DNA structure could alter the ability of YB-1 to efficiently recognize the other consensus sequences. Deletion of these sequences in the Stin2.9 domain may therefore result in the release from inhibition by binding of YB-1 to this site in the other variants. It should, however, be noted that in HEK 293T both Stin2.9 and Stin2.10 are activated by YB-1, although activation of the former was much more pronounced. This may be explained by the involvement of other cell specific modulators of Stin2.10 in HEK 293T cells, by different composition of YB-1 binding sites, or combination of these parameters resulting in activation of Stin 2.10 by YB-1 in HEK 293T cells. However, although YB-1 may interact differentially with the distinct consensus sequences, rp 6/7 and rp 3/4, a single base change in the consensus sequence could not only change the affinity and specificity of YB1 binding but also alter the complement of transcription factors capable of binding to the site. Because our data use purified transcription factors, we cannot rule out this possibility that other factors such as that postulated above to explain difference between reporter gene expression in HEK 293T and COS7 cells. Indeed, search for a transcription factor binding site using the program MatInspector (Genomatix Suite) predicts binding of several transcription factors to $\mathrm{rp} \mathrm{6/7}$ (GGCTGTGACCCGGGATGGGCTG). Among them are activator protein-1, Ikaros 2, TCF11/KCR-F1/Nrf1 homodimers, and retinoic acid receptor-related orphan receptor alpha1. These transcription factors could be expressed with a tissue-specific or stimulus-inducible pattern, raising an additional level of complexity to the regulation of the VNTR.

The interaction between $\mathrm{YB}-1$ and interacting partners such as CTCF is important for regulating the expression of several genes (Chernukhin et al., 2000). We therefore addressed whether CTCF would modulate either YB-1 binding to the VNTR or the ability of YB-1 to regulate reporter gene expression supported by the intron 2 VNTR. CTCF, as shown in Figure 2, by itself had little or no effect on reporter gene expression directed by the VNTR, however, it dramatically inhibited the ability of YB-1 to regulate VNTR supported promoter activity in the two cell lines tested. Consistent with this finding, CTCF antagonized YB-1 binding to the VNTR in EMSA studies (Fig. 3), but no evidence was observed for interaction of CTCF with the VNTR DNA sequence in EMSA.

To interrogate the mechanism by which CTCF antagonized YB-1 regulation of VNTR function, we performed the proteinbinding studies between YB-1 and CTCF outlined in Figure 4. These experiments demonstrate that CTCF will interact with YB-1 to form a protein complex via a region encompassing the DNA binding CSD, which constitutes the DNA-binding domain of YB-1. Although a more detailed mutational analysis would be required, these data are consistent with CTCF interactions abolishing the ability of YB-1 to bind to its consensus sequence, as exemplified by our EMSA data in Figure 3. Taken together, these observations suggest that a particular composition of the individual repeats in Stin2 VNTR and regulatory protein factors may result in different structural and regulatory configurations of this control region, which would support differential gene expression.

Our observations further extend previous findings demonstrating the significance of CTCF in the regulation of several neuronal genes (Vostrov and Quitschke, 1997; Yang et al., 1999; Burton et al., 2002; Vostrov et al., 2002; Hikichi et al., 2003; Ulaner et al., 2003) and the importance of YB-1 in the transcription of 
neurotropic viruses (Kerr et al., 1994; Del Valle et al., 2000). Thus, the mutual involvement of CTCF and YB-1 in the control of the 5-HTT VNTR brings yet another layer of complexity in their ability to regulate a wide variety of biological functions ranging from cancer to neurological disorders.

Our results also further substantiate a hypothesis that the individual elements within the VNTR domain differ in their ability to modulate transcriptional regulation in response to specific stimuli (Fiskerstrand et al., 1999; Lovejoy et al., 2003). As we demonstrate here, the VNTR elements can be activated by a transcription factor(s) (e.g., YB-1) and can also be subjected to feedback regulation, for example, by CTCF.

We therefore conclude that the transcription of the 5-HTT gene will be determined by the combinatorial action of multiple positive and negative promoter domains that specify the tissuespecific and stimulus-inducible expression of this gene (Quinn, 1996). The VNTR within intron 2 may have a direct effect on expression of the 5-HTT gene in specific cell types or in response to various physiological or pharmacological stimuli by synergizing with other 5-HTT promoter domains. This may correlate with the etiology or progression of affective disorders. By themselves, VNTR correlation with a susceptibility to the disorder may be low, however, because of their high frequency in the population, they may well have a major impact when complementing another risk factor. Demonstration of intron 2 VNTR as a differential enhancer would be consistent with our previous observations of the differential VNTR function exhibited in the initial serotoninergic regions of the developing CNS in transgenic models carrying the VNTR supported marker of gene expression (MacKenzie and Quinn, 1999; MacKenzie and Quinn, 2004). Furthermore, the concept of VNTR as a differential enhancer agrees with the hypothesis proposing that transient alterations in serotonin homeostasis cause permanent changes to adult behavior and modify the fine wiring of brain connections and that this may, in part, happen during development (Gaspar et al., 2003).

\section{References}

Battersby S, Ogilvie AD, Smith CA, Blackwood DH, Muir WJ, Quinn JP, Fink G, Goodwin GM, Harmar AJ (1996) Structure of a variable number tandem repeat of the serotonin transporter gene and association with affective disorder. Psychiatr Genet 6:177-181.

Bellivier F, Leroux M, Henry C, Rayah F, Rouillon F, Laplanche JL, Leboyer M (2002) Serotonin transporter gene polymorphism influences age at onset in patients with bipolar affective disorder. Neurosci Lett 334:17-20.

Burton T, Liang B, Dibrov A, Amara F (2002) Transforming growth factorbeta-induced transcription of the Alzheimer beta-amyloid precursor protein gene involves interaction between the CTCF-complex and Smads. Biochem Biophys Res Commun 295:713-723.

Casaregola S, Jacq A, Laoudj D, McGurk G, Margarson S, Tempete M, Norris V, Holland IB (1992) Cloning and analysis of the entire Escherichia coli ams gene. ams is identical to hmp1 and encodes a $114 \mathrm{kDa}$ protein that migrates as a $180 \mathrm{kDa}$ protein. J Mol Biol 228:30-40.

Chernukhin IV, Shamsuddin S, Robinson AF, Carne AF, Paul A, El-Kady AI, Lobanenkov VV, Klenova EM (2000) Physical and functional interaction between two pluripotent proteins, the Y-box DNA/RNA-binding factor, YB-1, and the multivalent zinc finger factor, CTCF. J Biol Chem 275:29915-29921.

Collier DA, Arranz MJ, Sham P, Battersby S, Vallada H, Gill AK, Sodhi M, Li T, Roberts GW, Smith B, Morton RM, Smith D, Kirov G (1996) The serotonin transporter is a potential susceptibility factor bipolar affectivedisorder. NeuroReport 7:1675-1679.

Conroy J, Meally E, Kearney G, Fitzgerald M, Gill M, Gallagher L (2004) Serotonin transporter gene and autism: a haplotype analysis in an Irish autistic population. Mol Psychiatry 9:587-593.

Del Valle L, Azizi SA, Krynska B, Enam S, Croul SE, Khalili K (2000) Reactivation of human neurotropic JC virus expressing oncogenic protein in a recurrent glioblastoma multiforme. Ann Neurol 48:932-936.
Didier DK, Schiffenbauer J, Woulfe SL, Zacheis M, Schwartz BD (1988) Characterization of the cDNA encoding a protein binding to the major histocompatibility complex class II Y box. Proc Natl Acad Sci USA 85:7322-7326.

Filippova GN, Fagerlie S, Klenova EM, Myers C, Dehner Y, Goodwin G, Neiman PE, Collins SJ, Lobanenkov VV (1996) An exceptionally conserved transcriptional repressor, CTCF, employs different combinations of zinc fingers to bind diverged promoter sequences of avian and mammalian c-myc oncogenes. Mol Cell Biol 16:2802-2813.

Fiskerstrand CE, Lovejoy EA, Quinn JP (1999) An intronic polymorphic domain often associated with susceptibility to affective disorders has allele dependent differential enhancer activity in embryonic stem cells. FEBS Lett 458:171-174.

Gaspar P, Cases O, Maroteaux L (2003) The developmental role of serotonin: news from mouse molecular genetics. Nat Rev Neurosci 4:1002-1012.

Gaudreault I, Guay D, Lebel M (2004) YB-1 promotes strand separation in vitro of duplex DNA containing either mispaired bases or cisplatin modifications, exhibits endonucleolytic activities and binds several DNA repair proteins. Nucleic Acids Res 32:316-327.

Heils A, Mossner R, Lesch KP (1997) The human serotonin transporter gene polymorphism - basic research and clinical implications. J Neural Transm 104:1005-1014.

Hikichi T, Kohda T, Kaneko-Ishino T, Ishino F (2003) Imprinting regulation of the murine Meg1/Grb10 and human GRB10 genes; roles of brainspecific promoters and mouse-specific CTCF-binding sites. Nucleic Acids Res 31:1398-1406.

Hoehe MR, Wendel B, Grunewald I, Chiaroni P, Levy N, Morris-Rosendahl D, Macher JP, Sander T, Crocq MA (1998) Serotonin transporter (5HTT) gene polymorphisms are not associated with susceptibility to mood disorders. Am J Med Genet 81:1-3.

Izumi $\mathrm{H}$, Imamura T, Nagatani G, Ise T, Murakami T, Uramoto H, Torigoe T, Ishiguchi H, Yoshida Y, Nomoto M, Okamoto T, Uchiumi T, Kuwano M, Funa K, Kohno K (2001) Y box-binding protein-1 binds preferentially to single-stranded nucleic acids and exhibits $3^{\prime} \rightarrow 5^{\prime}$ exonuclease activity. Nucleic Acids Res 29:1200-1207.

Jurchott K, Bergmann S, Stein U, Walther W, Janz M, Manni I, Piaggio G, Fietze E, Dietel M, Royer HD (2003) YB-1 as a cell cycle-regulated transcription factor facilitating cyclin A and cyclin B1 gene expression. J Biol Chem 278:27988-27996.

Kent L, Doerry U, Hardy E, Parmar R, Gingell K, Hawi Z, Kirley A, Lowe N, Fitzgerald M, Gill M, Craddock N (2002) Evidence that variation at the serotonin transporter gene influences susceptibility to attention deficit hyperactivity disorder (ADHD): analysis and pooled analysis. Mol Psychiatry 7:908-912.

Kerr D, Chang CF, Chen N, Gallia G, Raj G, Schwartz B, Khalili K (1994) Transcription of a human neurotropic virus promoter in glial cells: effect of YB-1 on expression of the JC virus late gene. J Virol 68:7637-7643.

Klenova EM, Nicolas RH, Paterson HF, Carne AF, Heath CM, Goodwin GH, Neiman PE, Lobanenkov VV (1993) CTCF, a conserved nuclear factor required for optimal transcriptional activity of the chicken c-myc gene, is an 11-Zn-finger protein differentially expressed in multiple forms. Mol Cell Biol 13:7612-7624.

Klenova EM, Nicolas RH, U S, Carne AF, Lee RE, Lobanenkov VV, Goodwin GH (1997) Molecular weight abnormalities of the CTCF transcription factor: CTCF migrates aberrantly in SDS-PAGE and the size of the expressed protein is affected by the UTRs and sequences within the coding region of the CTCF gene. Nucleic Acids Res 25:466-474.

Klenova EM, Chernukhin IV, El-Kady A, Lee RE, Pugacheva EM, Loukinov DI, Goodwin GH, Delgado D, Filippova GN, Leon J, Morse 3rd HC, Neiman PE, Lobanenkov VV (2001) Functional phosphorylation sites in the C-terminal region of the multivalent multifunctional transcriptional factor CTCF. Mol Cell Biol 21:2221-2234.

Klenova EM, Morse 3rd HC, Ohlsson R, Lobanenkov VV (2002) The novel BORIS + CTCF gene family is uniquely involved in the epigenetics of normal biology and cancer. Semin Cancer Biol 12:399-414.

Kohno K, Izumi H, Uchiumi T, Ashizuka M, Kuwano M (2003) The pleiotropic functions of the Y-box-binding protein, YB-1. BioEssays 25:691-698.

Lesch KP, Balling U, Gross J, Strauss K, Wolozin BL, Murphy DL, Riederer P (1994) Organization of the human serotonin transporter gene. J Neural Transm 95:157-162. 
Lovejoy EA, Scott AC, Fiskerstrand CE, Bubb VJ, Quinn JP (2003) The serotonin transporter intronic VNTR enhancer correlated with a predisposition to affective disorders has distinct regulatory elements within the domain based on the primary DNA sequence of the repeat unit. Eur J Neurosci 17:417-420.

MacDonald GH, Itoh-Lindstrom Y, Ting JP (1995) The transcriptional regulatory protein, YB-1, promotes single-stranded regions in the DRA promoter. J Biol Chem 270:3527-3533.

MacKenzie A, Quinn J (1999) A serotonin transporter gene intron 2 polymorphic region, correlated with affective disorders, has allele-dependent differential enhancer-like properties in the mouse embryo. Proc Natl Acad Sci USA 96:15251-15255.

MacKenzie A, Quinn JP (2004) Postgenomic approaches to exploring neuropeptide gene mis-expression in disease. Neuropeptides 38:1-15.

Mellerup E, Bennike B, Bolwig T, Dam H, Hasholt L, Jorgensen MB, Plenge P, Sorensen SA (2001) Platelet serotonin transporters and the transporter gene in control subjects, unipolar patients and bipolar patients. Acta Psychiatr Scand 103:229-233.

Ogilvie AD, Harmar AJ (1997) Association between the serotonin transporter gene and affective disorder: the evidence so far. Mol Med 3:90-93.

Ogilvie AD, Battersby S, Bubb VJ, Fink G, Harmar AJ, Goodwim GM, Smith CA (1996) Polymorphism in serotonin transporter gene associated with susceptibility to major depression. Lancet 347:731-733.

Ohlsson R, Renkawitz R, Lobanenkov V (2001) CTCF is a uniquely versatile transcription regulator linked to epigenetics and disease. Trends Genet 17:520-527.

Quinn JP (1996) Neuronal-specific gene expression-the interaction of both positive and negative transcriptional regulators. Prog Neurobiol 50:363-379.

Sambrook J, Russell DW (2001) Molecular cloning: a laboratory manual, Ed 3. Cold Spring Harbor, NY: Cold Spring Harbor Laboratory.

Smith DB, Johnson KS (1988) Single-step purification of polypeptides expressed in Escherichia coli as fusions with glutathione S-transferase. Gene 67:31-40.
Sommerville J, Ladomery M (1996) Masking of mRNA by Y-box proteins FASEB J 10:435-443.

Spitkovsky DD, Royer-Pokora B, Delius H, Kisseljov F, Jenkins NA, Gilber DJ, Copeland NG, Royer HD (1992) Tissue restricted expression and chromosomal localization of the YB-1 gene encoding a $42 \mathrm{kD}$ nuclear CCAAT binding protein. Nucleic Acids Res 20:797-803.

Swamynathan SK, Nambiar A, Guntaka RV (1998) Role of single-stranded DNA regions and $Y$-box proteins in transcriptional regulation of viral and cellular genes. FASEB J 12:515-522.

Ulaner GA, Yang Y, Hu JF, Li T, Vu TH, Hoffman AR (2003) CTCF binding at the insulin-like growth factor-II (IGF2)/H19 imprinting control region is insufficient to regulate IGF2/H19 expression in human tissues. Endocrinology 144:4420-4426.

Vostrov AA, Quitschke WW (1997) The zinc finger protein CTCF binds to the APBbeta domain of the amyloid beta-protein precursor promoter. Evidence for a role in transcriptional activation. J Biol Chem 272:33353-33359.

Vostrov AA, Taheny MJ, Quitschke WW (2002) A region to the N-termina side of the CTCF zinc finger domain is essential for activating transcription from the amyloid precursor protein promoter. J Biol Chem 277:1619-1627.

Wolffe AP (1994) Structural and functional properties of the evolutionarily ancient Y-box family of nucleic acid binding proteins. BioEssays 16:245-251.

Wolffe AP, Tafuri S, Ranjan M, Familari M (1992) The Y-box factors: a family of nucleic acid binding proteins conserved from Escherichia coli to man. New Biol 4:290-298.

Yang Y, Quitschke WW, Vostrov AA, Brewer GJ (1999) CTCF is essentia for up-regulating expression from the amyloid precursor protein promoter during differentiation of primary hippocampal neurons. J Neurochem 73:2286-2298.

Zasedateleva OA, Krylov AS, Prokopenko DV, Skabkin MA, Ovchinnikov LP, Kolchinsky A, Mirzabekov AD (2002) Specificity of mammalian Y-box binding protein p50 in interaction with ss and ds DNA analyzed with generic oligonucleotide microchip. J Mol Biol 324:73-87. 